\title{
Closure of Myelomeningocele Defects Using a Limberg Flap or Direct Repair
}

\author{
Jung-Hwan Shim ${ }^{1}$, Na-Hyun Hwang ${ }^{1}$, Eul-Sik Yoon ${ }^{1}$, Eun-Sang Dhong ${ }^{1}$, Deok-Woo Kim ${ }^{1}$, \\ Sang-Dae Kim ${ }^{2}$ \\ Departments of ${ }^{1}$ Plastic and Reconstructive Surgery and ${ }^{2}$ Neurosurgery, Korea University College of Medicine, Seoul, Korea
}

Background The global prevalence of myelomeningocele has been reported to be $0.8-1$ per 1,000 live births. Early closure of the defect is considered to be the standard of care. Various surgical methods have been reported, such as primary skin closure, local skin flaps, musculocutaneous flaps, and skin grafts. The aim of this study was to describe the clinical characteristics of myelomeningocele defects and present the surgical outcomes of recent cases of myelomeningocele at our institution.

Methods Patients who underwent surgical closure of myelomeningocele at our institution from January 2004 to December 2013 were included in this study. A retrospective chart review of their medical records was performed, and comorbidities, defect size, location, surgical procedures, complications, and the final results were analyzed.

Results A total of 14 patients underwent surgical closure for myelomeningocele defects. Twelve cases were closed with direct skin repair, while two cases required local skin flaps to cover the skin defects. Three cases of infection occurred, requiring incision and either drainage or removal of allogenic materials. One case of partial flap necrosis occurred, requiring secondary revision using a rotational flap and a full-thickness skin graft. Despite these complications, all wounds eventually healed completely.

Conclusions Most myelomeningocele defects can be managed by direct skin repair alone. In cases of large defects, in which direct repair is not possible, local flaps may be used to cover the defect. Complications such as wound dehiscence and partial flap necrosis occurred in this study; however, all such complications were successfully managed with simple ancillary procedures.

\section{Keywords Myelomeningocele / Surgical flap / Wound closure techniques}

\author{
Correspondence: Deok-Woo Kim \\ Department of Plastic and \\ Reconstructive Surgery, Korea \\ University College of Medicine, \\ 123 Jeokgeum-ro, Danwon-gu, \\ Ansan 15355, Korea \\ Tel: +82-31-412-4817 \\ Fax: +82-31-475-5074 \\ E-mail: deokwookim@gmail.com
}

This article was presented at the Fourth Research and Reconstructive Forum on April 3-4, 2014 in Busan, Korea.

No potential conflict of interest relevant to this article was reported.

Received: 16 Mar 2015• Revised: 25 Jun $2015 \bullet$ Accepted: 6 Jul 2015

pISSN: 2234-6163 • elSSN: 2234-6171 • http://dx.doi.org/10.5999/aps.2016.43.1.26 • Arch Plast Surg 2016;43:26-31

\section{INTRODUCTION}

Myelomeningocele is a form of spina bifida. At four weeks of gestation, the lateral edge of the neural plates elevate toward each other and fuse to form a tube known as the neural tube. Failure of this process results in a neural tube defect [1]. When the failure involves a posterior closure, it is called spina bifida [2]. While the etiology of neural tube defects remains poorly understood, recent studies have shown that genetics, geography, low socioeconomic status, and folic acid deficiency are factors associated with neural tube defects [3]. The global prevalence of myelomeningocele has been reported to be $0.8-1$ per 1,000 
live births $[4,5]$.

Closure of a large myelomeningocele defect is challenging for the reconstructive surgeon. The goals of closure are to preserve the function of the neural tissue and to prevent secondary infection [6]. If the myelomeningocele defect is small, direct repair can be performed; however, if the defect is large, various other reconstructive options are available [7]. In general, direct repair of myelomeningocele defects is performed in approximately $75 \%$ of cases, with the remaining $25 \%$ representing large myelomeningocele defects that require other methods of reconstruction [8]. Several reconstructive options exist for soft tissue closure, including local flaps, musculocutaneous flap variations, and skin grafting [9]. In this study, we report our ten-year experience with the treatment of myelomeningocele defects. We used direct repair or a Limberg flap to close the myelomeningocele defects, depending on the size of the defect.

\section{METHODS}

From January 2004 to December 2013, 14 patients with myelomeningocele defects underwent repair at our institution. Of these patients, eight (57\%) were male and six (43\%) were female, with a mean age of 67.4 days. Twelve patients (86\%) underwent direct repair, and two patients (14\%) underwent a Limberg flap procedure to cover the myelomeningocele defect. One patient required only one Limberg flap (Fig. 1), whereas the other patient required two Limberg flaps to cover the myelomeningocele defect (Fig. 2). In all patients, repair of the neu- ral tube and dura mater was performed by a neurosurgeon. In six patients, a small myelomeningocele skin defect was closed by the same neurosurgeon, and the other eight cases were repaired by a plastic surgeon. Patient demographics are summarized in Table 1. Retrospective chart review of medical records was performed and comorbidities, defect size, location, surgical procedures, complications, and the final results were analyzed.

\section{Surgical technique: the Limberg flap}

The Limberg flap is an example of a transposition flap. Although angles may vary, the Limberg flap is basically a parallelogram with two $120^{\circ}$ angles and two $60^{\circ}$ angles (Fig. 3). It is versatile in that a random pattern flap can be raised from any or all corners of the rhomboid. In the cases included in this study, the neurosurgeon covered the dural defect during standard dural repair. Artificial dural tissue (Neuro-Patch, B. Braun Melsungen AG, Melsungen, Germany) was used to cover the dural defect in two cases. The margin of the defect was then trimmed into a parallelogram to act as the Limberg flap. A vertical line equal to the length of one side of the rhomboidal defect was determined, followed by a second line parallel to one side of the rhombus. A skin incision was made to the muscle fascia first, and then the Limberg flap was dissected above the muscle fascia. After the dissection, the Limberg flap was transpositioned to the myelomeningocele defect.

\section{Surgical technique: direct repair}

Small myelomeningocele defects were covered by direct repair.

\section{Fig. 1. Single Limberg flap}

(A) One Limberg flap was planned to be placed in a patient with a myelomeningocele defect. (B) Image taken five months postoperatively.
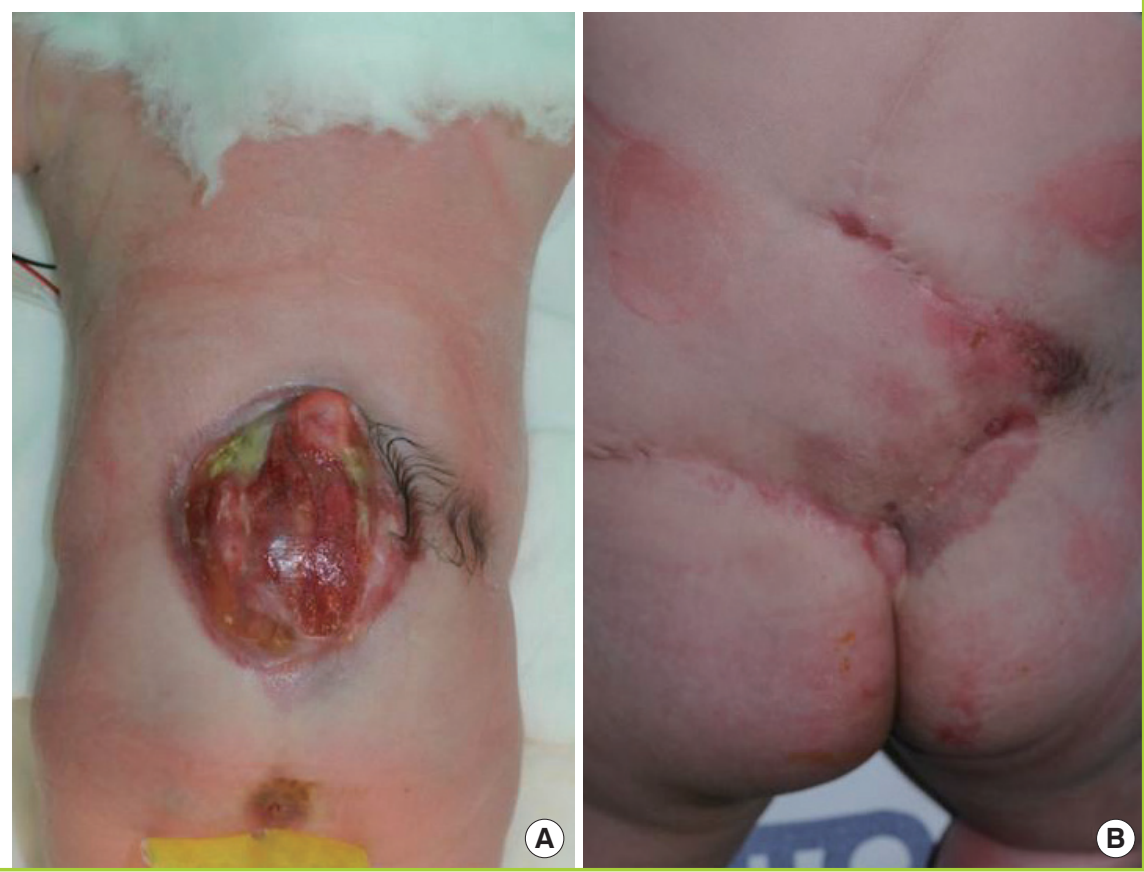


\section{Fig. 2. Two Limberg flaps}

(A) Two Limberg flaps were planned to be placed in a patient with a myelomeningocele defect. (B) A magnetic resonance image showing kyphosis of the thoracic spine and myelomeningocele. Note that the defect is shaped like a hemisphere, with a bulging surface. (C) Appearance of the flap one month after surgery. The black arrows indicate skin necrosis and wound dehiscence. A rotational flap and a full-thickness skin graft were performed. (D) Appearance of the flap three months after surgery.
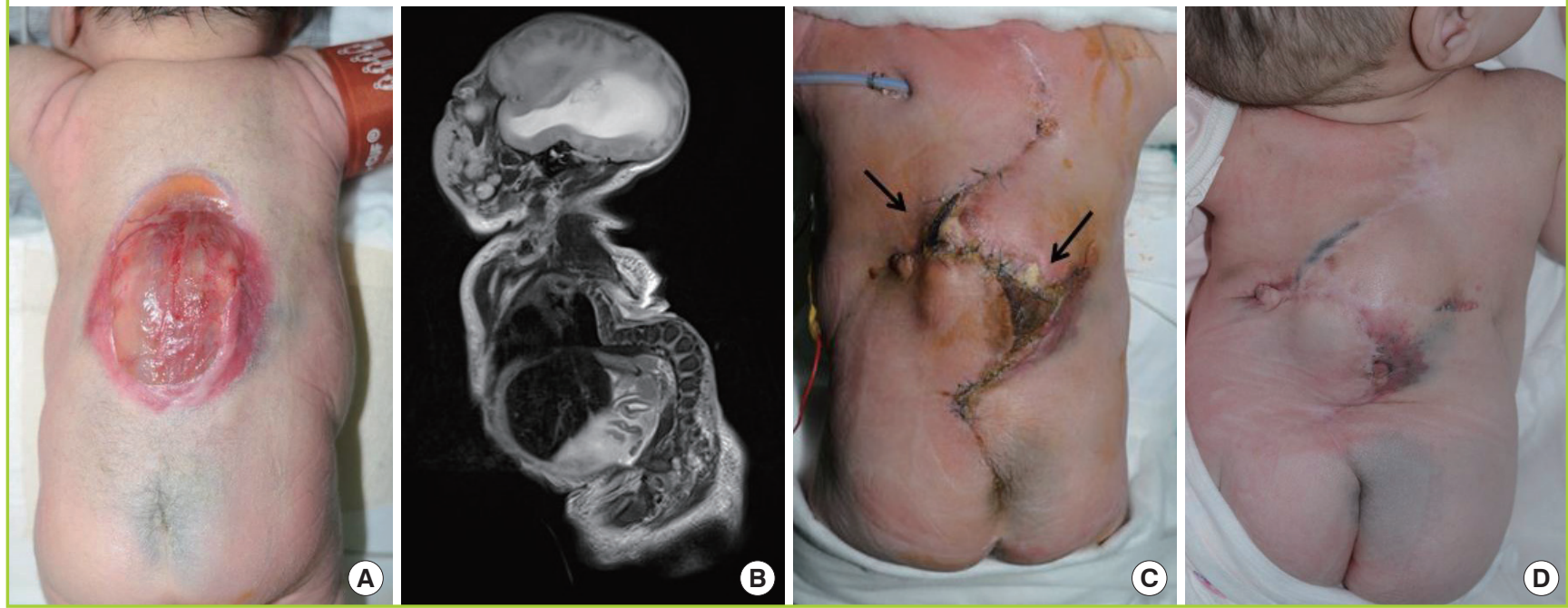

Table 1. Patient demographics

\begin{tabular}{|c|c|c|c|c|c|c|c|}
\hline $\begin{array}{l}\text { Patient } \\
\text { no. }\end{array}$ & Sex & $\begin{array}{l}\text { Age at } \\
\text { operation }\end{array}$ & $\begin{array}{l}\text { Size of defects } \\
\left(\mathrm{cm}^{2}\right)\end{array}$ & Procedure & Complications & Secondary procedures & Final result \\
\hline 1 & Male & $10 \mathrm{mo}$ & $1 \times 3$ & Direct repair & $\begin{array}{l}\text { 1. Infection } \\
\text { 2. Wound dehiscence }\end{array}$ & $\begin{array}{l}\text { 1. Incision and drainage } \\
\text { 2. Local advancement flap }\end{array}$ & Complete healing \\
\hline 2 & Female & 3 day & $2 \times 2$ & Direct repair & None & None & Complete healing \\
\hline 3 & Male & 3 day & $11 \times 1$ & Direct repair & None & None & Complete healing \\
\hline 4 & Male & 55 day & $5 \times 1$ & Direct repair & None & None & Complete healing \\
\hline 5 & Male & 19 day & $3 \times 1$ & Direct repair & None & None & Complete healing \\
\hline 6 & Male & 31 day & $8 \times 2$ & Direct repair & None & None & Complete healing \\
\hline 7 & Male & 3 day & $4 \times 2$ & Direct repair & None & None & Complete healing \\
\hline 8 & Female & 1 day & $5 \times 1$ & Direct repair & Infection & Debridement and direct repair & Complete healing \\
\hline 9 & Female & 2 day & $8 \times 8$ & Limberg flap & $\begin{array}{l}\text { 1. Infection } \\
\text { 2. Dehiscence and infection }\end{array}$ & $\begin{array}{l}\text { 1. Debridement and artificial dura removal } \\
\text { 2. Debridement and direct repair }\end{array}$ & Complete healing \\
\hline 10 & Male & 2 day & $9 \times 2$ & Direct repair & None & None & Complete healing \\
\hline 11 & Female & 12 day & $10 \times 1$ & Direct repair & None & None & Complete healing \\
\hline 12 & Female & $14 \mathrm{mo}$ & $15 \times 2$ & Direct repair & None & None & Complete healing \\
\hline 13 & Male & $3 \mathrm{mo}$ & $15 \times 1$ & Direct repair & None & None & Complete healing \\
\hline 14 & Female & 2 day & $8 \times 8$ & 2 Limberg flaps & Dehiscence and necrosis & Rotational flap and FTSG & Complete healing \\
\hline
\end{tabular}

FTSG, full-thickness skin graft.

After direct repair of the dural defect with non-absorbable sutures, an adjacent skin flap above the muscular layer was undermined to release tension, and the wound was closed directly.

\section{RESULTS}

A total of 14 patients underwent surgical closure of myelomeningocele defects. All patients except one had lumbosacral defects. One patient, in whom two Limberg flaps were used, developed a thoracic myelomeningocele defect. However, all defects were closed successfully. The mean follow-up period was 27 months (range, 3-112 months). The mean defect size was 9.4 $\mathrm{cm}^{2}$ in the direct repair cases and $64.0 \mathrm{~cm}^{2}$ in the Limberg flap cases. The average operative time was 190.9 minutes for direct repair and 220.0 minutes for the Limberg flaps (Table 2).

Both patients who underwent Limberg flap coverage developed hydrocephalus, and a ventriculoperitoneal shunt was required to decrease the pressure of the cerebrospinal fluid. Five of the 12 direct repair cases developed hydrocephalus, and two of these patients required a ventriculoperitoneal shunt. One 


\section{Fig. 3. Schematic diagram of a Limberg flap}

The wound is basically rhomboid, with two $120^{\circ}$ angles and two $60^{\circ}$ angles. We made a vertical line equal to the length of one side of the rhomboidal defect. Subsequently, a second line was made parallel to one side of the rhombus.

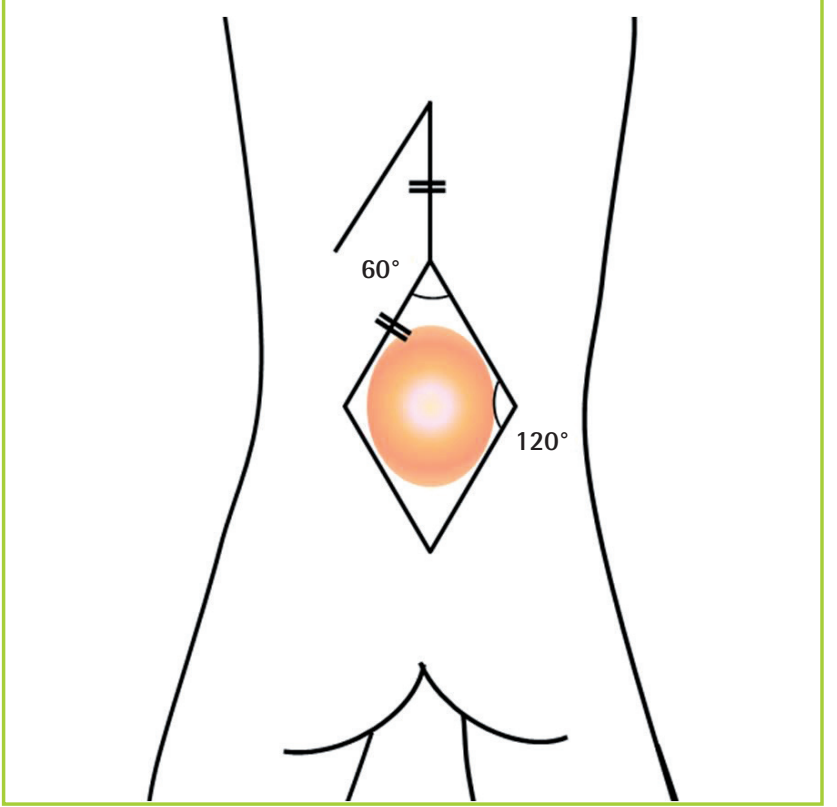

\section{Table 2. Summary of results}

\begin{tabular}{|lcc|}
\hline & \multicolumn{2}{c|}{ Group } \\
\cline { 2 - 3 } & Direct repair $(\mathrm{n}=\mathbf{1 2})$ & Limberg flap $(\mathrm{n}=\mathbf{2})$ \\
\hline Defect size $\left(\mathrm{cm}^{2}\right)$ & $9.42 \pm 5.52$ & $64 \pm 0$ \\
Operative time $(\mathrm{min})$ & $190.9 \pm 60.3$ & $220 \pm 21.2$ \\
Complications, $\mathrm{n}(\%)$ & $2(16.7)$ & $2(100)$ \\
\hline
\end{tabular}

Limberg flap case and five direct repair cases underwent a twodimensional echocardiogram shortly after birth. All six patients were diagnosed with patent foramen ovale (PFO). However, further evaluation of the PFO was unnecessary, because the size of the foramen was insignificant. Two Limberg flap cases and five direct repair cases underwent abdominal ultrasonography, and none showed any abnormalities in the abdominal cavity.

Complications developed after Limberg flap coverage in both patients (Table 3). One patient suffered from wound dehiscence with associated infection. The patient who underwent two Limberg flaps developed marginal flap necrosis and wound dehiscence at two different sites. Wound infection developed in two direct repair cases developed. Despite these complications, all wounds healed successfully after simple ancillary procedures.

Both patients who underwent Limberg flap coverage developed paraplegia. Of the remaining 12 patients, one expired due to an underlying condition, three developed weakness of the lower extremities, and eight were able to walk independently.
Table 3. Summary of complications

\begin{tabular}{|c|c|c|}
\hline \multirow{2}{*}{ Complication } & \multicolumn{2}{|c|}{ Group } \\
\hline & Direct repair $(n=12)$ & Limberg flap $(n=2)$ \\
\hline Infection & $2(16.7)$ & $1(50)$ \\
\hline Wound dehiscence & $1(8.3)$ & $2(100)$ \\
\hline Wound necrosis & 0 & $1(50)$ \\
\hline
\end{tabular}

\section{DISCUSSION}

Recently, fetal surgery for myelomeningocele repair has been introduced in some institutions and has been shown to result in improved neurological function and decreased morbidity [10]. However, fetal surgery is not preferred in many institutions due to the concerns of the parents or financial problems $[7,11]$. For these reasons, the postnatal closure of myelomeningocele is still considered the primary option for repairing myelomeningocele defects.

In previous studies, approximately $75 \%$ of myelomeningocele defects were closed by direct repair, while the remaining $25 \%$ required other reconstructive options [8]. Musculocutaneous flaps are an option for the closure of extremely wide myelomeningocele defects [12]. In 1978, McCraw et al. [13] reported a bilateral latissimus dorsi musculocutaneous flap for the closure of myelomeningocele, and bilateral latissimus dorsi musculocutaneous flaps with extended gluteal fasciocutaneous flaps have also been used [14]. Limberg latissimus dorsi musculocutaneous flaps [15], distally based latissimus dorsi flaps [2], and reverse latissimus dorsi musculocutaneous flaps [16] have also been used to close myelomeningocele defects. For lower sacral defects, a combination of latissimus dorsi and gluteus maximus musculocutaneous flaps was described by Ramirez et al. [17].

More recently, in 2012, Patel et al. [18] described local turnover fascial flaps and midline linear skin closure for the treatment of myelomeningocele defects. The use of perforator flaps, including lumbar artery perforator flaps, superior gluteal artery perforator flaps, and dorsal intercostal artery perforator flaps, has also been previously described $[19,20]$.

The use of local flaps for moderate to large lumbosacral myelomeningocele defects is considered a viable option. Many creative skin flaps have been described, such as bilobed flaps, double Z-rhomboid flaps, V-Y advancement flaps, rotation flaps, and Limberg flaps [5,21-23]. In 1979, Ohtsuka et al. [23] first described the use of the Limberg flap for closing myelomeningocele defects. Later, Cruz et al. [21] emphasized the utility of Limberg flaps for the closure of myelomeningocele. To our knowledge, this is the first report in Korea that provides support for 


\section{Fig. 4. Schematic diagram of two Limberg flaps}

(A) The design of two Limberg flaps: one at the top and one at the bottom of the defect. (B) Two Limberg flaps were rotated to the center of the defect. Both ends of these flaps overlapped (gray shading) at the center of the defect, allowing three-dimensional resurfacing of the defect.

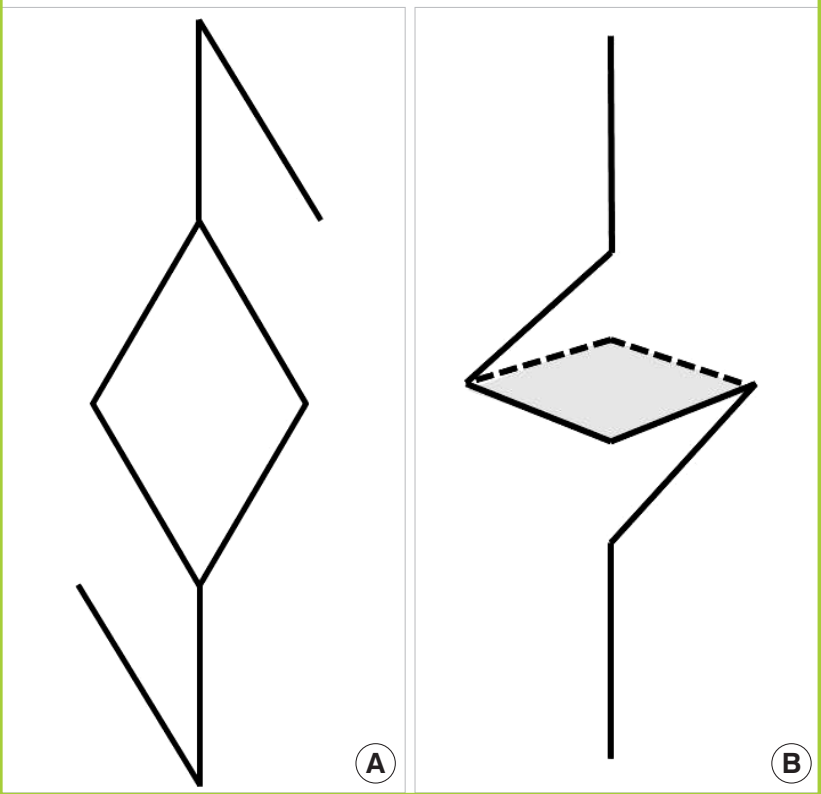

the use of the Limberg flap in the closure of myelomeningocele defects. Since myelomeningocele is a disease with a very low incidence, it was difficult for us to compare different surgical techniques more thoroughly. However, this article may be used as a reference point for future studies.

We chose the Limberg flap to cover lumbosacral myelomeningocele defects for several reasons. Some reports have suggested that it is advantageous to use a V-Y advancement flap, which leaves a vertical midline scar, for a secondary operation [18]. However, closure of the defect using a V-Y advancement flap did not seem possible in our patients due to a lack of sufficient skin on the lateral side. Additionally, the use of relaxing incisions is not feasible in cases of midline closure. In the Limberg flap, it is possible to use redundant skin from the scapular to upper thoracic area. Excess tension may arise due to insufficient circulation to the distal tip of the flap, but this problem resolves eventually, since the center of the defect is covered by the flap core, in which the circulation is stable. Marginal necrosis in the midline closure may pose a more serious problem.

In our two cases requiring Limberg flaps, the defect was hemispherical, with a bulging surface area approximately 1.5 times larger than that of the corresponding plane surface, with mechanical pressure concentrated in the bulging surface (Fig. 2). This configuration may result in dehiscence of the midline closure. If two Limberg flaps are created, one at the top of the de- fect and one at the bottom of the defect, both ends of these flaps will overlap, allowing three-dimensional resurfacing at the center of the defect (Fig. 4).

The Limberg flap has several additional advantages. In musculocutaneous or perforator flaps, the operating time is prolonged, thereby prolonging the anesthetic time, which may adversely affect the general condition of young patients. We found some perforators in our patients, but the size of the perforators was not reliable. The Limberg flap is also frequently performed to cover rectangular or round defects, because it has the advantage of preserving the back muscles, so that patients can maintain correct trunk posture as they grow up, and because the procedure can be performed with minimal blood loss [7]. Limberg flaps can fully cover large myelomeningocele defects (up to $8 \times 8$ $\mathrm{cm}^{2}$ in our study). Theoretically, all sides of a rhomboid defect can be used as flaps, meaning that a total of four flaps can be elevated at once.

Some complications occurred in our Limberg flaps. However, in one case, the complications were associated with an infection of the allogenic materials, not with the flap itself. One patient developed marginal necrosis, which was a flap-related complication; however, it was easily reversed, and complete healing was eventually achieved.

In our opinion, simple closure should be the treatment of choice for small myelomeningocele defects. However, single or multiple rhomboid (Limberg) flaps can be applied very safely to treat larger defects (up to $64 \mathrm{~cm}^{2}$ ). Extremely large defects may, however, require more complicated surgical procedures, involving musculocutaneous flaps.

\section{REFERENCES}

1. Wallingford JB. Neural tube closure and neural tube defects: studies in animal models reveal known knowns and known unknowns. Am J Med Genet C Semin Med Genet 2005; 135C:59-68.

2. Scheflan M, Mehrhof AI Jr, Ward JD. Meningomyelocele closure with distally based latissimus dorsi flap. Plast Reconstr Surg 1984;73:956-9.

3. Botto LD, Moore CA, Khoury MJ, et al. Neural-tube defects. N Engl J Med 1999;341:1509-19.

4. Greenberg F, James LM, Oakley GP Jr. Estimates of birth prevalence rates of spina bifida in the United States from computer-generated maps. Am J Obstet Gynecol 1983; 145: 570-3.

5. Lapid O, Rosenberg L, Cohen A. Meningomyelocele reconstruction with bilobed flaps. Br J Plast Surg 2001;54:570-2.

6. El-khatib HA. Large thoracolumbar meningomyelocele de- 
fects: incidence and clinical experiences with different modalities of latissimus dorsi musculocutaneous flap. Br J Plast Surg 2004;57:411-7.

7. Campobasso P, Pesce C, Costa L, et al. The use of the Limberg skin flap for closure of large lumbosacral myelomeningoceles. Pediatr Surg Int 2004;20:144-7.

8. Patterson TJ. The use of rotation flaps following excision of lumbar myelo-meningoceles: an aid to the closure of large defects. Br J Surg 1959;46:606-8.

9. Zide BM. Spina bifida. In: McCarthy JG, editor. Plastic surgery. Philadelphia: Saunders; 1990. p.3780-90.

10. Adzick NS. Fetal surgery for spina bifida: past, present, future. Semin Pediatr Surg 2013;22:10-7.

11. Muskett A, Barber WH, Parent AD, et al. Contemporary postnatal plastic surgical management of meningomyelocele. J Plast Reconstr Aesthet Surg 2012;65:572-7.

12. Mustarde JC. Reconstruction of the spinal canal in severe spina bifida. Plast Reconstr Surg 1968;42:109-14.

13. McCraw JB, Penix JO, Baker JW. Repair of major defects of the chest wall and spine with the latissimus dorsi myocutaneous flap. Plast Reconstr Surg 1978;62:197-206.

14. McDevitt NB, Gillespie RP, Woosley RE, et al. Closure of thoracic and lumbar dysgraphic defects using bilateral latissimus dorsi myocutaneous flap transfer with extended gluteal fasciocutaneous flaps. Childs Brain 1982;9:394-9.

15. Munro IR, Neu BR, Humphreys RP, et al. Limberg-latissimus dorsi myocutaneous flap for closure of myelomeningo- cele. Childs Brain 1983;10:381-6.

16. VanderKolk CA, Adson MH, Stevenson TR. The reverse latissimus dorsi muscle flap for closure of meningomyelocele. Plast Reconstr Surg 1988;81:454-6.

17. Ramirez OM, Ramasastry SS, Granick MS, et al. A new surgical approach to closure of large lumbosacral meningomyelocele defects. Plast Reconstr Surg 1987;80:799-809.

18. Patel KB, Taghinia AH, Proctor MR, et al. Extradural myelomeningocele reconstruction using local turnover fascial flaps and midline linear skin closure. J Plast Reconstr Aesthet Surg 2012;65:1569-72.

19. El-Sabbagh AH, Zidan AS. Closure of large myelomeningocele by lumbar artery perforator flaps. J Reconstr Microsurg 2011;27:287-94.

20. Duffy FJ Jr, Weprin BE, Swift DM. A new approach to closure of large lumbosacral myelomeningoceles: the superior gluteal artery perforator flap. Plast Reconstr Surg 2004;114: 1864-8.

21. Cruz NI, Ariyan S, Duncan CC, et al. Repair of lumbosacral myelomeningoceles with double Z-rhomboid flaps. Technical note. J Neurosurg 1983;59:714-7.

22. Habal MB, Vries JK. Tension free closure of large meningomyelocele defects. Surg Neurol 1977;8:177-80.

23. Ohtsuka H, Shioya N, Yada K. Modified Limberg flap for lumbosacral meningomyelocele defects. Ann Plast Surg 1979; 3:114-7. 